\title{
A robust method to identify cyclone tracks from gridded data
}

\author{
F. Kreienkamp, A. Spekat, and W. Enke \\ Climate \& Environment Consulting Potsdam GmbH, David-Gilly-Str. 1, 14469 Potsdam, Germany
}

Received: 26 March 2010 - Revised: 25 October 2010 - Accepted: 4 November 2010 - Published: 15 November 2010

\begin{abstract}
A system to derive tracks of barometric minima is presented. It is deliberately using coarse input data in space (order of $2^{\circ} \times 2^{\circ}$ ) and time (6-hourly to daily) as well as information from just one geopotential level. It is argued that the results are, for one robust in the sense of an assumption of the IMILAST Project that the use of as simple as possible metrics should be strived for and for two tailored to the input from reanalyses and GCMs. The methodology presented is a necessary first step towards an automated storm track recognition scheme which will be employed in a second paper to study the future development of atmospheric dynamics in a changing climate. The process towards obtaining storm tracks is two-fold. In its first step cyclone centers are being identified. The performance of this step requires the existence of closed isolines, i.e., a topology in which a grid-point is surrounded by neighbours which all exhibit higher geopotential. The usage of this topology requirement as well as the constraint of coarse data may lead, though, to limitations in identifying centers in geopotential fields with shallow gradients that may occur in the summer months; moreover, some centers may potentially be missed in case of a configuration in which a small scale storm is located at the perimeter of a deep and very large low (a kind of "dent in a crater wall"). The second step of the process strings the identified cyclone centers together in a meaningful way to form tracks. By way of several examples the capability to identify known storm tracks is shown.
\end{abstract}

\section{Introduction}

This study focuses on the identification and tracking of moving low pressure systems. It is the result of a project initialized by the Regional Environment Agency of Saxonia and thus has an emphasis on tracks with relevance to Central Europe. The method applied has large scale as well as regional scale elements - the data source for the the identification consists of NCAR reanalysis data (Kalnay et al., 1996) from 1951-2006. Developing such an algorithm on a rather coarse spatially and temporally resolved basis leads to a robust tool to address issues such as the classification of dynamic circulation aspects and the study of cyclone tracks, e.g., in global climate model data.

Similar to the classification of circulation patterns into socalled Großwetterlagen, first attempts towards a classification system for storm tracks in the European sector were carried out at the end of the 19th century. The meteorologist Wilhelm Jacob van Bebber published his system - which

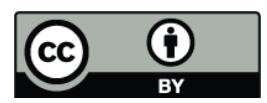

Correspondence to: F. Kreienkamp (frank.kreienkamp@cec-potsdam.de) has been in use ever since - in 1891 in Meteorologische Zeitschrift (van Bebber, 1891). The formative influence to his approach was maritime meteorology, in particular the identification of "heavy weather". His requirement was that there are preferred pathways for the movement of storms into central and eastern Europe. The van Bebber classification, as shown in Fig. 1, however, was based on observations from only a few years and station network of rather low density.

The system includes tracks with relevance for the British Isles, the North-Eastern Atlantic, the North Sea and the Baltic in its groups I through IV as well as one group, V, with a more southerly placement leading across Western Europe into the Mediterranean Sea, branching off towards Northern Africa, the Balkans or the Eastern Mediterranean area. To this date, track $\mathrm{Vb}$ of the latter group has remained in common use, unlike the large majority of van Bebber's tracks. Frequently, a connection is established between the advance of intense cyclones from the Mediterranean area on the one hand and particularly intense precipitation events on the other. So-called $V b$-situations are, e.g., linked to flooding events in the summer of 1997 (Odra river) and 2002 (Elbe river). It should be added that the North-Western Mediterranean Sea and the Gulf of Genova in particular are not 


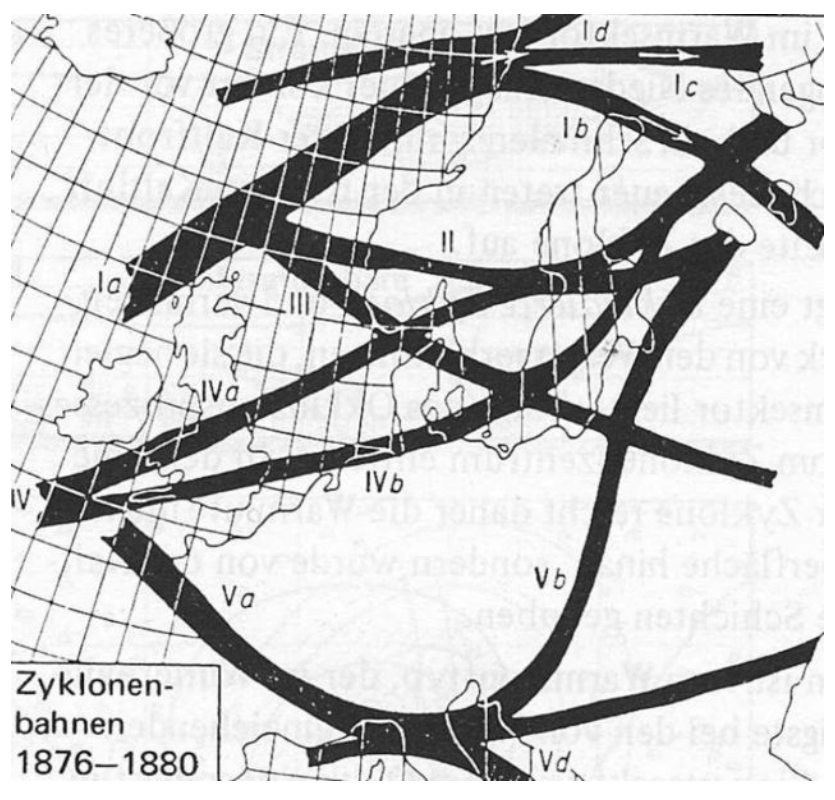

Figure 1. Storm tracks according to van Bebber (1891).

mere transition areas for passing cyclones but areas of frequent cyclogenesis. In Petterssen (1956) chapter 13, maps are given that show the occurrence and the genesis of cyclones in the entire Northern Hemisphere which highlight the cyclone activity in the Mediterranean Basin, particularly in winter. Recent publications, e.g., Lionello et al. (2006), Anagnostopoulou et al. (2006), Homar et al. (2007) or Lionello and Giorgi (2007) focus on present and future cyclone climatologies for this area.

Already in the first half of the 20th century synoptic studies of the connection between the strength of the atmospheric flow and the displacement of cyclones/anticyclones were being carried out (e.g., Rossby, 1939). In the 1980s and 1990s the discussion of existence, frequency and future modification of storm tracks was reviewed (e.g., Lau, 1988). The progress in the development of atmosphere models led to particular involvement of moving intense cyclones as identifiers of the modelled climate's dynamics, as e.g., Bengtsson (1991) summarized. Moreover, cyclones of that kind have a major impact, e.g. on the extremes of wind and precipitation. An interesting point of the atmospheric dynamics and storm tracks is discussed in Hoskins and Valdes (1990). The authors note a puzzling contradiction: A cyclone center moves as a consequence of the atmosphere system's tendency to achieve an energy balance. The baroclinic instability in a region should be reduced by a moving system. Why, the authors are asking, are there frequent similar tracks, often used in rapid succession? There ought to be a mechanism which sustains baroclinic instability despite this flagging process. Their conclusion, based on comparably coarse assumptions of the climate system's components and low resolution climate models was that the heating by ocean currents, such as the Gulf Stream triggers the formation of a corridor in which cyclones propagate.

The concept of a corridor has been picked up by other authors, who consider van Bebber's cyclone tracks as bundles in a genesis and propagation area, such as the entire North Atlantic. Studies in conjunction with future emission scenarios have been published, e.g. by Lambert (1995), Carnell et al. (1996) or Schubert et al. (1998). Bengtsson et al. (2006) conclude in a comprehensive study that the Northern Atlantic and Scandinavia in particular will be subjected to a future increase in cyclone activity while the track branches into the Mediterranean area (the V-group of van Bebber), rated as a secondary track system, will decrease in importance. A drop in Mediterranean cyclone activity as a consequence of $\mathrm{CO}_{2}$ doubling had been found by Lionello et al. (2002). More recent studies (Lionello et al., 2008) based on climate models with a higher resolution confirm these findings. Pinto et al. (2006) show evidence of a decline in Mediterranen cyclone activity including cyclogenesis in the Gulf of Genova. They add that Central Europe is an area jointly influenced by cyclones moving in from the Atlantic as well as the Mediterranean Sea and that there is an indication in the scenarios that this will remain the case in the future.

The Fourth IPCC Assessment Report (IPCC, 2007) includes summaries concerning cyclone tracks in several chapters:

- Observations (Trenberth et al., 2007): There is a poleward displacement of the storm tracks; the frequency of cyclones is reduced but their intensity increases. Climate variability with respect to extratropical lows is large and the problem of track identification becomes larger because of constant changes in the observation system.

- Climate Models (Randall et al., 2007): Simulated cyclone tracks have a stronger zonal orientation as the observed ones.

- Understanding and Attributing Climate Change (Hegerl et al., 2007): The poleward displacement of the main tracks, as observed in the last 50 years will continue into the future with high probability.

- Global Climate Projections (Meehl et al., 2007): The poleward displacement of the tracks can be attributed in part to the expansion of the subtropical Hadley circulation - future changes in precipitation would thus occur even if the cyclone intensity remains unchanged.

- Regional Climate Projections (Christensen et al., 2007): There is a predominant probability that the wind will decrease in the Mediterranean area and increase over Northern Europe. The modifications of the cyclone tracks have a clear influence on winter precipitation. 
As stated above, the identification of cyclone tracks is a research field that dates back at least to the late 19th century. A review of the methods employed in detecting and tracking cyclones, including the methods' evolution over time, can be found in Raible et al. (2008). In that paper it is also pointed out that cyclone frequency and track climatologies exhibit major differences depending on the methodologies employed. This sparked the establishment of the IMILAST (Intercomparison of MId-LAtitude STorm diagnostics) project in $2009^{1}$ which is to be finished in 2011. The IMILAST tasks range from a survey of methods (more than 20 methods are documented!) to assess their individual uncertainties which may lead to a set of recommendations concerning purpose-specific tracking strategies. On the Background Web Page of IMILAST it is emphasized that The use of as simple as possible metrics should be strived for. Techniques that aim for simplicity and easy reproducibility are the focus of several studies, e.g., Hanson et al. (2004).

Common to most methods is a two step procedure: First a cyclone detection scheme is devised, followed by a cyclone tracking procedure. The methodologies employed by different working groups cover a broad range. In exemplary form, three strategies will be briefly described. The approach of Blender and Schubert (2008) identifies minima of the $1000 \mathrm{hPa}$ geopotential field (z1000) within a neighbourhood of 8 grid points of a reference point. In order to be able to include very weakly developed centers, a minimum gradient $(20 \mathrm{gpm}$ per $1000 \mathrm{~km})$ in a given area (radius $1000 \mathrm{~km}$ ) is required. The centers which were so identified are lined up to form cyclone tracks by a next-neighbour search. An other strategy is suggested by Wernli and Schweiz (2006). They are also identifying the cyclones as local minima in the z1000 field. A local minimum is required to be surrounded by a closed contour which is $15 \mathrm{gpm}$ higher than this local minimum. The cyclone tracks are sought by calculating a potential position for the next time step as a first guess. Then the candidate in greatest proximity of that first guess position within a $1000 \mathrm{~km}$ perimeter is chosen. Sinclair (1997) has focused particulary on the cyclone identification aspect. In a first step a preproceesing is applied to remove scale dependence in the needed atmospheric fields followed by a smoothing according to Cressman (1959). According to synoptic experience, it is rather difficult to identify atmospheric minima in the Southern Hemisphere; there, cyclones are identified as local maxima of the cyclonic gradient wind vorticity which is required to surpass a threshold. Then, the first guess strategy is applied when constructing the tracks: A predicted position is compared with the cyclone position as it occurs in the subsequent time step.

The authors have developed their own approach to produce a tracking algorithm that is as straightforward and simple as possible - similar to what IMILAST is proposing. Only the geopotential in a coarse grid of about $2^{\circ} \times 2^{\circ}$ is evaluated.

\footnotetext{
${ }^{1}$ http://www.proclim.ch/imilast/index.html
}

This makes the method applicable to long-term climatologies such as NCEP reanalyses, as well as to GCM scenarios of the IPCC-AR4 generation. The term robust is to be interpreted in the context of the method's ability to identify the cyclone centers and produce cyclone tracks from coarse input.

\section{Data}

$850 \mathrm{hPa}$ geopotential height data from NCEP reanalyses (Kalnay et al., 1996) were used in the study to develop the identification methods for cyclone centers and tracks. They establish a three-dimensional climatology of the atmosphere for the time frame 1950 until now. The "alternative product", which has been generated by ECMWF (ERA40, Uppala et al., 2005) is available just until 2002 and cannot be used to study the immediate past. There are other products, such as ERA interim, which extend into the immediate past and have a higher resolution. Yet, they do not extend far enough back to establish a useful climatology - for that, at least 30 years would be required. It is noteworthy that due to a higher model internal resolution (ERA40 (T106) to NCEP (T62)) ERA40 is able to produce a greater number of cyclones (Raible et al., 2008). This may be one reason why not all observed cyclones can be found by the used method.

In conjunction with the aforementioned focus on Central Europe, the study has been carried out in an area enclosed by a rectangle of 38 zonal grid-points $(28.125 \mathrm{~W}$ to $43.125 \mathrm{E})$ and 36 meridional grid-points $(21.45 \mathrm{~N}$ to $88.57 \mathrm{~N})$. Some cyclone centers in subsequent figures might not have been labelled, since they are outside this area.

\section{Method and discussion}

A straightforward and pragmatic system was developed which derives the positions of the minima in the gridded 6hourly geopotential fields (cf. Sect. 3.1). Using a set of displacement criteria those minima are stringed together to form tracks. This produces a catalogue of storm tracks as well as a wealth of information concerning size, intensity and displacement of the moving lows.

\subsection{Identification of cyclone centers}

A center is defined as an individual, contained minimum which is surrounded by larger values in all directions. Small, shallow lows which are a mere dent in a much larger cyclone can only be detected if there are appropriate neighbouring grid points within the spatial resolution of the grid point data set. Finding the deepest cyclone in a geopotential field is a trivial exercise - it is just necessary to determine the field's minimum.

A thought experiment may be carried out to illustrate the next steps of the approach: Imagine the reservoir of a dam which has flooded a settlement. If we assume the water level 


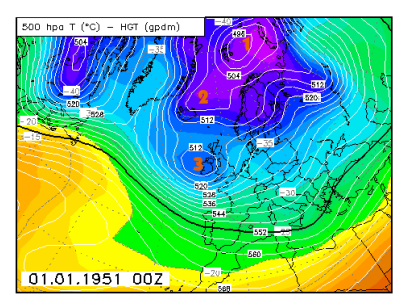

(a)

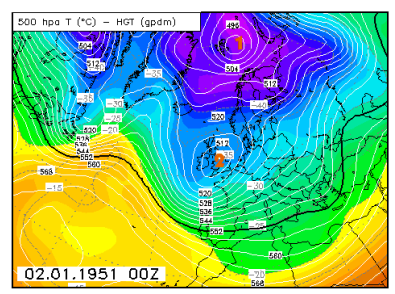

(c)

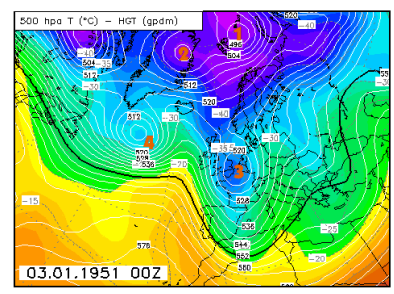

(e)

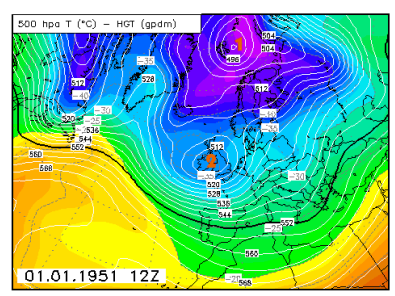

(b)

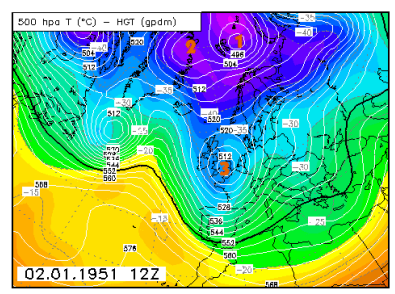

(d)

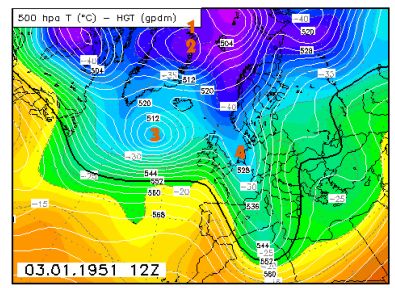

(f)

Figure 2. Series of $500 \mathrm{hPa}$ charts from 1 to 3 January 1951 (Source: www.wetterzentrale.de). The centers found by the identification algorithm are plotted in red; they are sorted by the intensity of the cyclone.

to drop, individual structures and building re-appear ${ }^{2}$. Perhaps the bell tower of a church (center of the strongest cyclone). Then the top of a smaller belfry (center of a secondary cyclone with the second-lowest core pressure). Then maybe the top of a high building (center of a tertiary cyclone). With further retreat of the water, another roof may appear, and so on. The search algorithm has to be capable of finding connected "buildings" as well as "building parts". This is achieved by stepwise lowering of the water level (raising of the reference level) until the first structure shows. A new structure is recognized as soon as subsequent water level lowering (reference pressure rise) yields only points which have lower pressure than the (successively raised) reference pressure. Figures 2 and 3 show examples for identified centers.

The $500 \mathrm{hPa}$ level has been chosen just for illustration purposes, since centers are particularly clear in this level of low divergence - the identification itself uses the $850 \mathrm{hPa}$ geopo-

\footnotetext{
${ }^{2}$ There is a twist to the thought experiment, since we are dealing with low pressure structures and thus the picture has to be imagined upside down.
}

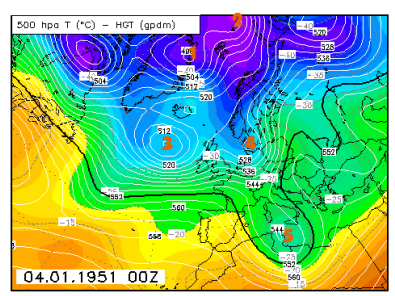

(a)

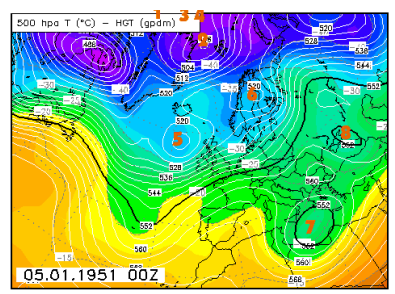

(c)

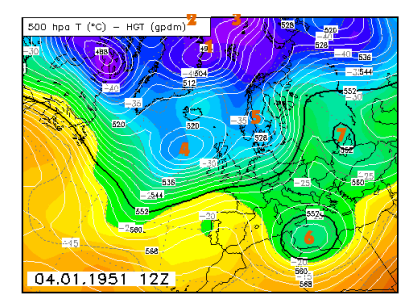

(b)

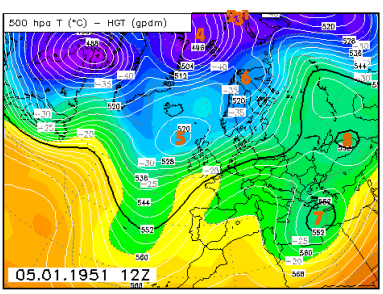

(d)
Figure 3. As in Fig. 2, but for 4 and 5 January 1951.

tential level. Surface pressure data would be an option but they pose several problems: (i) It would be problematic to track cyclones over elevated terrain ${ }^{3}$ (ii) in comparison with upper air data, the structures which are to be identified exhibit a higher degree of detail which reduces the efficiency of the center-finding algorithm, and (iii) particularly in winter, the surface level is frequently decoupled from cyclone activity by inversions which also reduces the efficiency of the algorithm. The identification of centers is carried out in steps of $6 \mathrm{~h}$ - the chart archive used for illustration, on the other hand, contains just $00 \mathrm{z}$ and $12 \mathrm{z}$ information. A few remarks concerning the charts, Figs. 2 and 3 :

- 1 Jan 00z: There were three cyclones identified, which are numbered according to their depth. The trough near the northern Ural was not identified as an individual cyclone because no closed isoline could be constructed within the grid resolution (cf. Sect. 2). However, low \#2 fulfilled this criterium. The strong cyclone over the Hudson Bay is outside the identification window used for this study.

- 1 Jan 12z: Only two centers were identified, since the trough to the north-east of Iceland was not sufficiently large to fulfil the criteria - this is again the case on 2 Jan 00z (Fig. 2c), while on 2 Jan $12 z$ (Fig. 2d) a size is re-gained that enables identification.

- The charts of 3 Jan $12 \mathrm{z}$ and subsequent dates (Figs. $2 \mathrm{f}$ and 3) frequently contain numbered centers on the upper edge. The related cyclones, identified by the algorithm

${ }^{3}$ In $2^{\circ} \times 2^{\circ}$ resolution, the topography of continental Europe is generally below $1500 \mathrm{~m}$, making $850 \mathrm{hPa}$ a more suitable level for the study. 
are outside the range of the map. Moreover, it is possible that centers have no label; in such a case the cyclone would be outside the investigation window mentioned in Sect. 2.

In addition to the position and the geopotential height of the center, the "number of pixels" a measure of the area covered by the cyclone is registered - each pixel being a grid point. It is the number of grid points in the $38^{\circ} \times 36^{\circ}$ field which are topologically assigned to an individual cyclone.

\subsection{Identification of tracks}

As illustrated in the previous section each chart contains "candidates" for moving cyclones but in nature there are also formation and dissolution processes as well as phases in which the identification algorithm is unable to find a closed center. For each date, i.e., every six hours, all cyclones are entered into the calculation in ascending order of their core geopotential. The track-forming algorithm is considering all cyclones that are entirely within the $38^{\circ} \times 36^{\circ}$ field. In order to relate the individual positions $P$ of the $n$ centers at time step $T$ to those at the subsequent time step $T+1$ a similarity matrix for each center $P_{n}(T) \Rightarrow P_{m}(T+1)$ is formed. $T$ and $T+1$ denote the time steps which are $6 \mathrm{~h}$ apart. The maximum allowed $D$ for two consecutive positions is 10 . The similarity measure evaluates three components with individual weights:

1. Distance $D$ between the centers (weight: 4 ) which is calculated as $D=\left|i_{T}-i_{T+1}\right|+\left|j_{T}-j_{T+1}\right|$ with $i$ being the meridional component (number of the grid point in the $38^{\circ} \times 36^{\circ}$ field) and $j$ being its zonal component.

2. Difference $Z$ in geopotential between the centers at time steps $T$ and $T+1$ (weight: 2 ).

3. Difference $A$ in the number of pixels (see above) between the cyclones (weight: 1)

An aspect of item 1 above should be pointed out: The grid used is not equidistant and there is a potential for bias when assessing cyclone displacement in a kilometric sense to the effect that some tracks may not be captured if cyclones move (i) extremely fast, (ii) on a zonally oriented track and (iii) in very high latitudes. In an example shown later in this paper (cf. Table 2) a displacement of up to $\approx 400 \mathrm{~km}$ occurs for a very fast moving cyclone in $60^{\circ} \mathrm{N}$, whereas the maximum $D$ would be $\approx 1100 \mathrm{~km}$ in that latitude which compares to the $1000 \mathrm{~km}$ assumed in Wernli and Schweiz (2006). Since our study has a target area in Central Europe this bias, although it may occur, is of less relevance.

The similarity matrix is often incomplete because on a given date $T$ there might be, e.g., cyclones 1, 4 and 7 eligible for track construction whereas on time step $T+1$ cyclones 2 , 4, 5 and 6 might be candidates.
Table 1. Storm track of a cyclone near the British Isles between 1 and 4 January, 1951. Level: $500 \mathrm{hPa}$.

\begin{tabular}{ccccc}
\hline Day & Date & Storm No. & Latitude & Longitude \\
\hline 1 Jan 51 & 00 & 3 & $55.0 \mathrm{~N}$ & $11.3 \mathrm{~W}$ \\
& 06 & 2 & $53.2 \mathrm{~N}$ & $11.3 \mathrm{~W}$ \\
& 12 & 2 & $53.2 \mathrm{~N}$ & $5.6 \mathrm{~W}$ \\
& 18 & 2 & $55.0 \mathrm{~N}$ & $1.9 \mathrm{~W}$ \\
2 Jan 51 & 00 & 2 & $55.0 \mathrm{~N}$ & $1.9 \mathrm{~W}$ \\
& 06 & 2 & $53.2 \mathrm{~N}$ & $1.9 \mathrm{~W}$ \\
& 12 & 3 & $51.3 \mathrm{~N}$ & $0.0 \mathrm{~W}$ \\
& 18 & 3 & $51.3 \mathrm{~N}$ & $1.9 \mathrm{E}$ \\
3 Jan 51 & 00 & 3 & $51.3 \mathrm{~N}$ & $3.8 \mathrm{E}$ \\
& 06 & 4 & $51.3 \mathrm{~N}$ & $5.6 \mathrm{E}$ \\
& 12 & 4 & $53.2 \mathrm{~N}$ & $5.6 \mathrm{E}$ \\
& 18 & 4 & $55.0 \mathrm{~N}$ & $7.5 \mathrm{E}$ \\
4 Jan 51 & 00 & 4 & $55.0 \mathrm{~N}$ & $9.4 \mathrm{E}$ \\
\hline
\end{tabular}

Table 2. Track of the storm "Anatol" from Iceland across the German Bight into the area of the Baltic States, between 2 and 5 December 1999. Level: $500 \mathrm{hPa}$.

\begin{tabular}{ccccc}
\hline Day & Date & Storm No. & Latitude & Longitude \\
\hline 2 Dec 99 & 06 & 2 & $64.4 \mathrm{~N}$ & $15.0 \mathrm{~W}$ \\
& 12 & 2 & $64.4 \mathrm{~N}$ & $11.3 \mathrm{~W}$ \\
& 18 & 2 & $64.4 \mathrm{~N}$ & $11.3 \mathrm{~W}$ \\
3 Dec 99 & 00 & 2 & $64.4 \mathrm{~N}$ & $11.3 \mathrm{~W}$ \\
& 06 & 2 & $58.8 \mathrm{~N}$ & $3.8 \mathrm{~W}$ \\
& 12 & 2 & $56.9 \mathrm{~N}$ & $3.8 \mathrm{E}$ \\
& 18 & 1 & $58.8 \mathrm{~N}$ & $11.3 \mathrm{E}$ \\
4 Dec 99 & 00 & 1 & $58.8 \mathrm{~N}$ & $16.9 \mathrm{E}$ \\
& 06 & 1 & $58.8 \mathrm{~N}$ & $22.5 \mathrm{E}$ \\
& 12 & 1 & $58.8 \mathrm{~N}$ & $28.1 \mathrm{E}$ \\
5 Dec 99 & 18 & 1 & $58.8 \mathrm{~N}$ & $31.9 \mathrm{E}$ \\
& 00 & 1 & $58.8 \mathrm{~N}$ & $35.6 \mathrm{E}$ \\
& 06 & 3 & $60.6 \mathrm{~N}$ & $39.4 \mathrm{E}$ \\
\hline
\end{tabular}

The algorithm identifies the minima of $D, Z$ and $A$ between all candidate centers at two time steps. In that phase, tentative track segments are generated. If they are shorter than eight consecutive time steps, i.e., $48 \mathrm{~h}$, they are discarded. Tracks would end at the time step with a displacements of $D>10$ or if they are not completely in the investigation window any more or if they leave the window altogether. Examples are given in Tables 1 and 2.

The displacement of the cyclone can be traced in Figs. 2 and $3, \operatorname{too}^{4}$. The longitude and latitude entries refer to the positions of the grid points that were evaluated. Column Storm No makes reference to the centers which are identified at that particular date and ordered by magnitude. On 1 January 1951 (Fig. 2a), the low, labelled "3", can be found

\footnotetext{
${ }^{4}$ Note that the figures just show the $00 \mathrm{z}$ and $12 \mathrm{z}$ conditions, whilst the Table lists positions every $6 \mathrm{~h}$.
} 


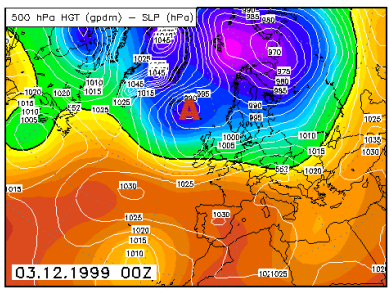

(a)

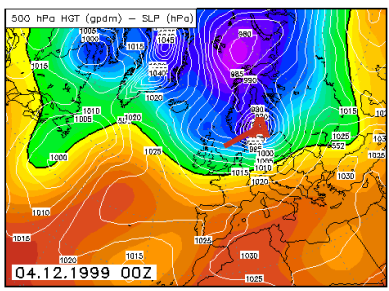

(c)

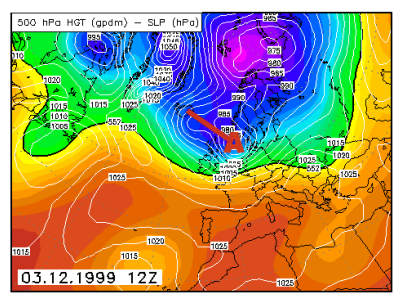

(b)

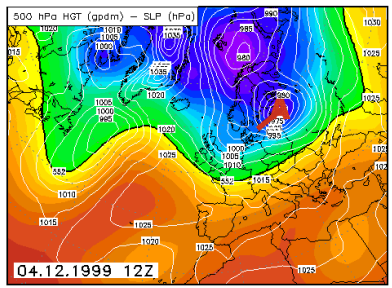

(d)

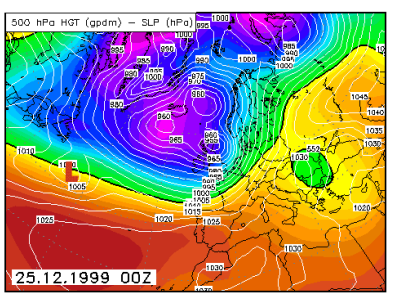

(a)

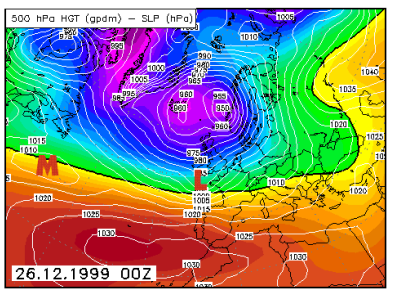

(c)

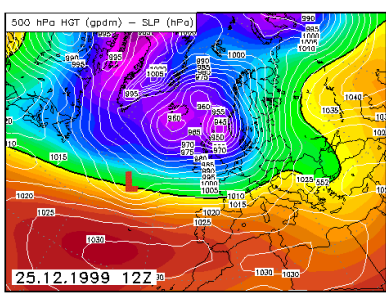

(b)

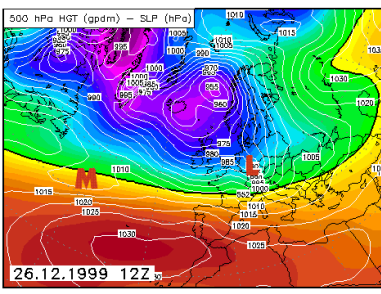

(d)
Figure 4. Section of the track of storm "Anatol" (the center is indicated by the letter A) in the sea level pressure field on 3 and 4 December 1999 (white isolines). The 12-h displacement of the center is marked by a red line in subfigure (b)-(d). The center's positions found on 2 December 06z until 5 December 06Z are given in Table 2 .

east of the British Isles. An intermediate stadium is included in the 06z row of that day in Table 1. It indicates a westward motion. The center can thus be found at $12 \mathrm{z}$ over Northern Ireland (Fig. 2a). Between 18z, 1 January and 12z, 2 January only very little motion is visible. Then the center begins its eastbound track along the 51st parallel. This motion receives an additional northward component (cf. center "4" in Fig. 2f) between 3 January $12 \mathrm{z}$ and 4 January 00z. Simultaneously, a bubble-like motion towards the Mediterranean Sea occurs. It develops into a cutting-off low which, on 4 January 00z (Fig. 3a) appears so markedly that an individual center is recognized. The new Mediterranean cyclone is moving only very little, nevertheless it can be identified until 6 January (not fully covered in the displayed sequence of charts). The previous track of the center that remained in Central Europe can be traced across the Baltic Sea into Northern Scandinavia. The cyclone arrives at the Kola Peninsula on 5 January $12 \mathrm{z}$ (cf. Fig. 3d).

Table 2 shows the example of a track identification for a very fast moving storm which occurred in the first December days of 1999 and received the name "Anatol" by the Meteorologists from the Free University of Berlin ${ }^{5}$. It developed from a trough in the North Atlantic between Greenland and Iceland and moved only little until 3 January 00z. After that it deepened quickly and moved swiftly across the northern Central Europa towards the Baltic States.

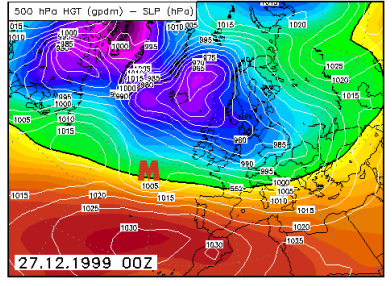

(a)

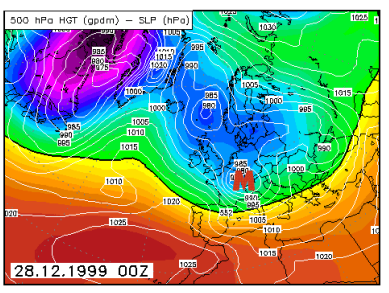

(c)

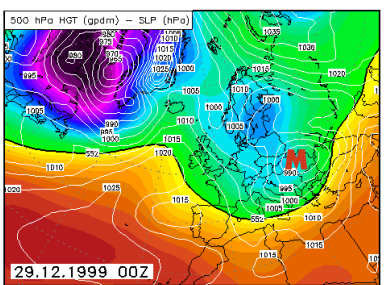

(e)

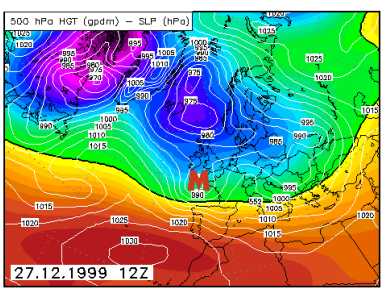

(b)

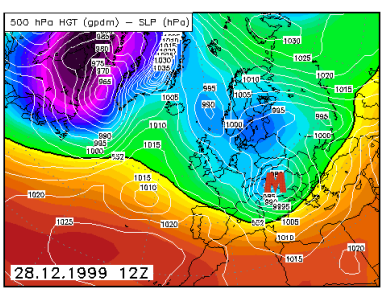

(d)

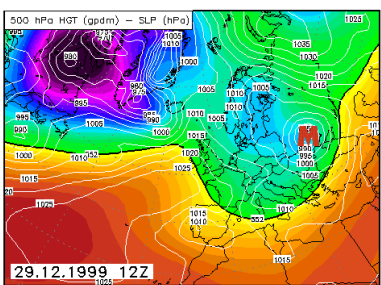

(f)
Figure 6. Section of the track of storm "Martin" (the center is denoted "M") in the sea level pressure field between 27 and 29 December 1999 (white lines).

${ }^{5}$ http://www.met.fu-berlin.de/adopt-a-vortex/ 


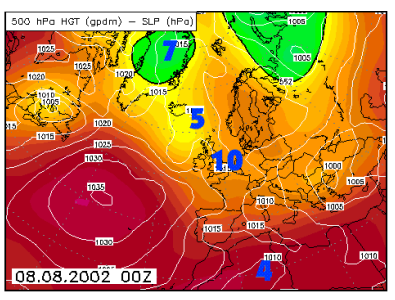

(a)

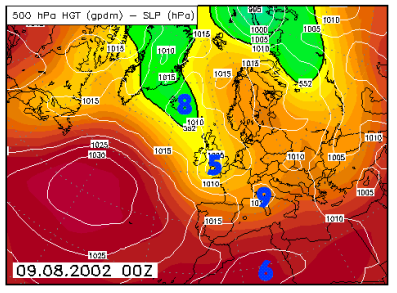

(c)

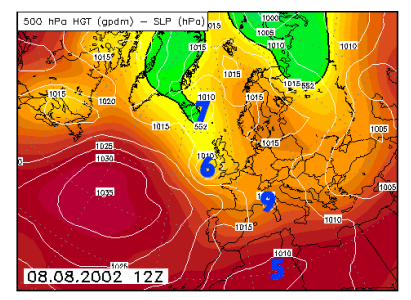

(b)

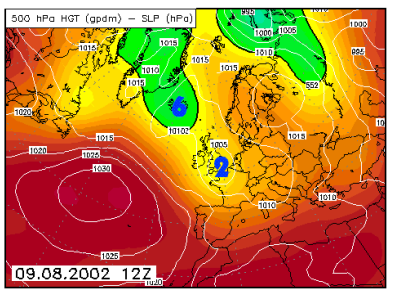

(d)

Figure 7. Example of a sequence of summer days: Sea level pressure field on 8 and 9 August 2002 (white lines). A selection of identified cyclone centers are numbered in blue.

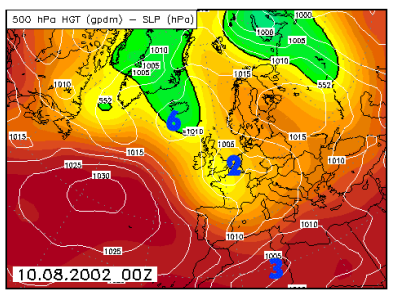

(a)

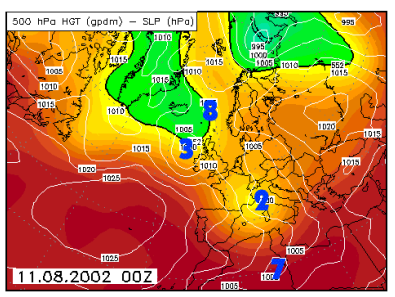

(c)

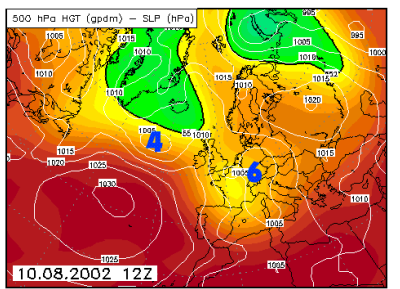

(b)

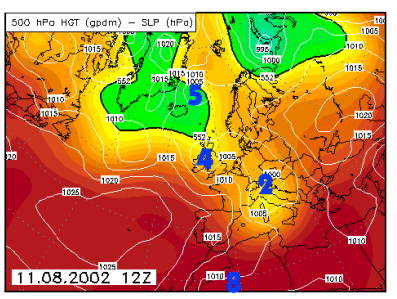

(d)

Figure 8. As in Fig. 7, but for 10 and 11 August 2002.

The episode which is relevant for Central Europe has been displayed in four surface pressure charts (Fig. 4). As shown in Table 2 the low was the second largest in the map area up to 3 December $12 \mathrm{z}$ - the strongest could be found near the hemispheric cold center over the Arctic Sea near Spitsbergen. Thereafter and until 5 December, "Anatol" had the lowest core pressure in the entire map sector.

The displacement speed exceeded, in particular in the phase over the Eastern Atlantic and the North Sea, 7 degrees of longitude (on the order of $400 \mathrm{~km}$ in that region) in $6 \mathrm{~h}$ !

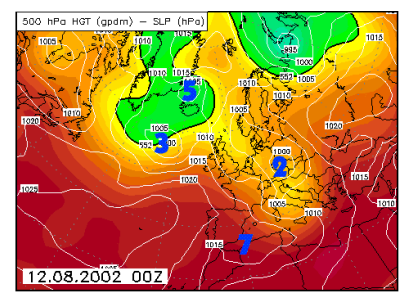

(a)

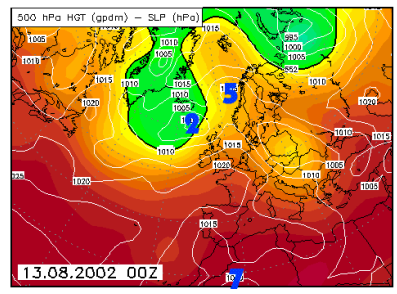

(c)

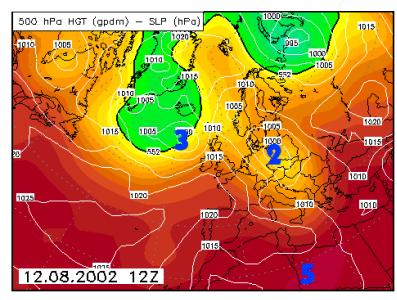

(b)

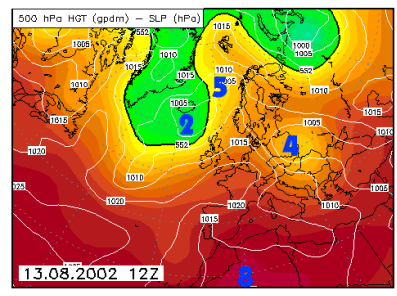

(d)
Figure 9. As in Fig. 7, but for 12 and 13 August 2002.

The tracking criteria of the identification algorithm are, as just shown, capable of a dependable recognition of a continuous storm track. The path of storm "Lothar", however, could not be identified in full. For one, the geographical resolution of the data set $\left(2^{\circ} \times 2^{\circ}\right)$ is too coarse, for two "Lothar" was moving towards Central Europe at the edge of a very large and intense Arctic Sea low - consisting of several centers and for three, even in its most intense stadium, "Lothar" had a very small closed isobar (cf. Fig. $1 \mathrm{~b}$ and d in Ulbrich et al. (2001)).

As can be seen in Fig. 5, a cyclone with a closed isobar around the center is located East of Newfoundland on 25 December $00 \mathrm{z}$. Its position, west of $30 \mathrm{~W}$, is outside the map area of this study. Subsequently, "Lothar" is a mere marginal dent in the outer reaches of an extended Arctic Sea cyclone with a strong pressure gradient.

The paradox stated in Hoskins and Valdes (1990), where it is pointed out that it appears unusual that storm tracks are used several times in succession has an interesting reflection in the events of the days following 2 December. Already on 26 December, a further cyclogenesis occurs near Newfoundland. The storm, known under the name "Martin" (denoted "M" in Fig. 5c and d), develops. The evolution during the following days is shown in Fig. 6.

In the case of "Martin" the algorithm which identifies storm centers was able to find closed isobars and generate a storm track. This is due to the changed synoptic situation, because the strong Artic Sea low which was dominant during the track of "Lothar" had weakened after 27 December at a great distance near the hemispheric cold center, located over the Canadian Arctic at that time, another very strong low was forming. Thus a comparably weak gradient over the North Sea and Central Europe caused "Martin" to stand out much more clearly and a successful track identification was possible. 
The flow regime of the transition seasons and the winter is characterized by strong gradients which simplifies the centers' identification and the tracking in comparison to summer. A final example from 2002 may help illustrating this fact.

As an important result the analysis of summer data yielded that the center identification algorithm frequently found 6 to 10 centers in a chart - in winter conditions this number is are clearly smaller. Yet the temporal sequence of positions only leads to a few tracks. Figures 7-9 show the genesis and propagation of a cyclone which caused large amounts of rain in Central Europe. As an extreme example, between 12 August 2002 07z and 13 August 2002 the rainfall amount at the Saxon station Zinnwald-Georgenfeld was $312 \mathrm{~mm}$ (Fritzschner and Lux, 2002). It caused the Elbe flooding, inflicting major damage to infrastructure across the area, including the historic center of Dresden.

The weather process in the first half of August 2002 was characterized by repeated cyclone advances from the Atlantic and the Mediterranean. The problematic track identification process is evident in the chart sequence Fig. 7. The cyclones have a weather impact rather because of their thermal and hydrometeorological properties than because of their dynamics (weak gradients and coherence) ${ }^{6}$. Charts of temperature and humidity of the lower troposphere (not shown here) indicate that there was a high potential for intense precipitation at that time.

Fritzschner and Lux (2002) attribute the precipitation event that led to the Elbe flooding to a van Bebber Vb situation. In fact, the charts indicate, starting on 10 August (Fig. 8a, intermittently the second strongest center in the investigation area) the development of a shallow extended low which expanded westward into Central and Southern Europe (Fig. 8c). The cyclogenesis was most pronounced to the south of the Alps (at that and the following dates indicated by the number " 2 "). The center moved slowly to the north-east, in phase with the upper air current (Fig. 9, denoted "2" in (a) and (b) and " 4 " in (c) and (d)), triggering sustained heavy rain. The criteria for a $V b$ cyclones were met almost in a textbook-like way. Nevertheless, Fritzschner and Lux (2002) point out that cyclone developments and tracks of that type seldom are the single cause for heavy rain.

\section{Summary, conclusions and outlook}

The aim of the study was the development of an algorithm that can identify storm tracks in an objective manner. An important application would be the analysis of GCM data in order to determine future developments in climate dynamics as they would emerge from the changing placement of storm tracks and intensity of storms.

${ }^{6}$ Please note that the coloured bands in the figures do not represent the temperature but the $500 \mathrm{hPa}$ geopotential height.
A method has been presented that is capable of determining storm tracks in gridded geopotential/surface pressure data sets of rather coarse spatial and temporal resolution, as they are provided by reanalyses and GCMs. It combines a geometric identification scheme for local minima with a set of rules to determine highly probable tracks from the arrays of identified centers in subsequent fields.

The center recognition performance depends on the existence of closed isolines, i.e., a topology in which a gridpoint is surrounded by neighbours which all exhibit higher geopotential. For cyclones that are lined up to form storm tracks these requirements are well met. A few exceptions are the relatively shallow fields that may occur in the summer months and a configuration in which a small scale storm is located at the perimeter of a deep and very large low (a kind of "dent in a crater wall").

The actual assembly of the tracks from individual centers takes into account that the motion along the track should stick to several criteria: For one, a track is accepted if it lasts for at least $48 \mathrm{~h}$ (eight consecutive time steps); furthermore there should be no displacement larger than 10 grid points (of the $\approx 2^{\circ} \times 2^{\circ}$ input data) from time step to time step. By way of several examples the capability to identify knowns storm tracks was shown.

This paper focuses on the description of the tracking algorithm. In a subsequent paper the classification of storm tracks will be addressed. Comparisons with the historic classification of van Bebber will need to be made.

Acknowledgements. This work was made possible by funds from the State of Saxony, grant AZ 13-8802.3529/47.

Thanks are due to the two anonymous referees for their constructive comments that helped to improve the manuscript substantially.

Edited by: M. Piringer

Reviewed by: H. Scheifinger and another anonymous referee

\section{References}

Anagnostopoulou, Chr., Tolika, K., Flocas, H., and Maheras, P.: Cyclones in the Mediterranean region: present and future climate scenarios derived from a general circulation model (HadAM3P), Adv. Geosci., 7, 9-14, doi:10.5194/adgeo-7-9-2006, 2006.

Bengtsson, L.: Advances and prospects in numerical weather prediction, Q. J. Roy. Meteor. Soc., 117, 855-902, 1991.

Bengtsson, L., Hodges, K., and Roeckner, E.: Storm Tracks and Climate Change, J. Climate, 19, 3518-3543, 2006.

Blender, R. and Schubert, M.: Cyclone tracking in different spatial and temporal resolutions, Mon. Weather Rev., 128, 377-384, 2008.

Carnell, R., Senior, C., and Mitchell, J.: An assessment of measures of storminess: Simulated changes in northern hemisphere winter due to increasing $\mathrm{CO}_{2}$., Clim. Dynam., 12, 467-476, 1996.

Christensen, J., Hewitson, B., Busuioc, A., Chen, A., Gao, X., Held, I., Jones, R., Kolli, R., Kwon, W.-T., Laprise, R., Rueda, V. M., Mearns, L., Menéndez, C., Räisänen, J., Rinke, A., Sarr, A., and Whetton, P.: Regional Climate Projections, in: Climate Change 
2007: The Physical Science Basis. Contribution of Working Group I to the Fourth Assessment Report of the Intergovernmental Panel on Climate Change , edited by: Solomon, S., Qin, D., Manning, M., Chen, Z., Marquis, M., Averyt, K. B., Tignor, M., and Miller, H. L., Cambridge Unversity Press, Cambridge, UK and New York, USA, Chap. 11, 847-940, 2007.

Cressman, P.: An operational objective analysis system, Mon. Weather Rev., 87, 548-553, 1959.

Fritzschner, U. and Lux, G.: Starkniederschläge in Sachsen im August 2002, Tech. Rep., Deutscher Wetterdienst, 2002.

Hanson, C., Palutikof, J., and Davies, T.: Objective cyclone climatologies of the North Atlantic - a comparison between the ECMWF and NCEP Reanalyses, Clim. Dynam., 22, 757-769, 2004.

Hegerl, G., Zwiers, F., Braconnot, P., Gillett, N., Luo, Y., Orsini, J. M., Nicholls, N., Penner, J., and Stott, P.: Understanding and Attributing Climate Change, in: Climate Change 2007: The Physical Science Basis. Contribution of Working Group I to the Fourth Assessment Report of the Intergovernmental Panel on Climate Change, edited by: Solomon, S., Qin, D., Manning, M., Chen, Z., Marquis, M., Averyt, K. B., Tignor, M., and Miller, H. L., Cambridge University Press, Cambridge, UK and New York, USA, Chap. 9, 663-746, 2007.

Homar, V., Jansà, A., Campins, J., Genovés, A., and Ramis, C.: Towards a systematic climatology of sensitivities of Mediterranean high impact weather: a contribution based on intense cyclones, Nat. Hazards Earth Syst. Sci., 7, 445-454, doi:10.5194/nhess-7445-2007, 2007.

Hoskins, B. and Valdes, P.: On the existence of storm-tracks, J. Atmos. Sci., 47, 1854-1864, 1990.

IPCC: Climate Change 2007: The Physical Science Basis. Contribution of Working Group I to the Fourth Assessment Report of the Intergovernmental Panel on Climate Change, Cambridge University Press, Cambridge, UK and New York, USA, ISBN: 9780521 70596-7, 2007.

Kalnay, E., Kanamitsu, M., Kistler, R., Collins, W., Deaven, D., Gandin, L., Iredell, M., Saha, S., Whitea, G., Woolen, J., Zhu, Y., Chelliah, M., Ebisuzaki, W., Higgins, W., Janowiak, J., Mo, K., Ropelewski, C., Wang, J., Leetmaa, A., Reynolds, R., Jenne, R., and Joseph, D.: The NCEP/NCAR 40-year Reanalysis Project, B. Am. Meteorol. Soc., 77, 437-471, 1996.

Lambert, S.: The effect of enhanced greenhouse warming on winter cyclone frequencies and strengths, J. Climate, 8, 1447-1452, 1995.

Lau, N.-C.: Variability of the observed midlatitude storm tracks in relation to low-frequency changes in the circulation pattern, J. Atmos. Sci., 45, 2718-2743, 1988.

Lionello, P. and Giorgi, F.: Winter precipitation and cyclones in the Mediterranean region: future climate scenarios in a regional simulation, Adv. Geosci., 12, 153-158, doi:10.5194/adgeo-12153-2007, 2007.

Lionello, P., Dalan, F., and Elvini, E.: Cyclones in the Mediterranean region: The present and the doubled $\mathrm{CO}_{2}$ climate scenarios, Clim. Res., 22, 147-159, 2002.

Lionello, P., Malanotte-Rizzoli, P., and Boscolo, R. (Eds.): Mediterranean Climate Variability, Elsevier, 2006.

Lionello, P., Boldrin, U., and Giorgi, F.: Future changes in cyclone climatology over Europe as inferred from a regional climate simulation, Clim. Dynam., 30, 657-671, 2008.
Meehl, G., Stocker, T., Collins, W., Friedlingstein, P., Gaye, A., Gregory, J., Kitoh, A., Knutti, R., Murphy, J., Noda, A., Raper, S., Watterson, I., Weaver, A., and Zhao, Z.-C.: Global Climate Projections, in: Climate Change 2007: The Physical Science Basis. Contribution of Working Group I to the Fourth Assessment Report of the Intergovernmental Panel on Climate Change, edited by: Solomon, S., Qin, D., Manning, M., Chen, Z., Marquis, M., Averyt, K. B., Tignor, M., and Miller, H. L., Cambridge University Press, Cambridge, UK and New York, USA, Chap. 10, 747-846, 2007.

Petterssen, S.: Weather Analysis and Forecasting, Vol. I, Motion and Motion Systems, 2nd Edn., McGraw-Hill Book Company, 1956.

Pinto, J., Spangehl, T., Ulbrich, U., and Speth, P.: Assessment of winter cyclone activity in a transient ECHAM4-OPYC3 GHG experiment, Meteorol. Z., 15, 279-291, 2006.

Raible, C., Della-Marta, P., Schwierz, C., Wernli, H., and Blender, R.: Northern Hemisphere Extratropical Cyclones: A Compaision of Detection and Tracking Methods and Different Reanalyses, Mon. Weather Rev., 136, 880-897, 2008.

Randall, D., Wood, R., Bony, S., Colman, R., Fichefet, T., Fyfe, J., Kattsov, V., Pitman, A., Shukla, J., Srinivasan, J., Stouffer, R., Sumi, A., and Taylor, K.: Climate Models and Their Evaluation, in: Climate Change 2007: The Physical Science Basis. Contribution of Working Group I to the Fourth Assessment Report of the Intergovernmental Panel on Climate Change, edited by: Solomon, S., Qin, D., Manning, M., Chen, Z., Marquis, M., Averyt, K. B., Tignor, M., and Miller, H. L., Cambridge University Press, Cambridge, UK and New York, USA, Chap. 8, 589-662, 2007.

Rossby, C.: Relation Between Variations in the Intensity of the Zonal Circulation of the Atmosphäre and the Displacements of the Semi-Permanent Centers in Action, J. Mar. Res., 2, 38-55, 1939.

Schubert, M., Perlwitz, J., Blender, R., Fraedrich, K., and Lunkeit, F.: North Atlantic cyclones in $\mathrm{CO}_{2}$ induced warm climate simulations: Frequency, intensity, and tracks., Clim. Dynam., 14, 827-837, 1998.

Sinclair, M.: Objective Identification of Cyclones and Their Circulation Intensity, and Climatology, Weather Forecast., 12, 595612, 1997.

Trenberth, K., Jones, P., Ambenje, P., Bojariu, R., Easterling, D., Tank, A. K., Parker, D., Rahimzadeh, F., Renwick, J., Rusticucci, M., Soden, B., and Zhai, P.: Observations: Surface and Atmospheric Climate Change. In: Climate Change 2007: The Physical Science Basis. Contribution of Working Group I to the Fourth Assessment Report of the Intergovernmental Panel on Climate Change, edited by: Solomon, S., Qin, D., Manning, M., Chen, Z., Marquis, M., Averyt, K. B., Tignor, M., and Miller, H. L., Cambridge University Press, Cambridge, UK and New York, USA, Chap. 3, 235-336, 2007.

Ulbrich, U., Fink, A., Klawa, M., and Pinto, J.: Three extreme storms over Europe in December 1999, Weather, 56, 70-80, 2001.

Uppala, S., Kållberg, P., Simmons, A., Andrae, U., da Costa Bechtold, V., Fiorino, M., J., J. G., Haseler, Hernandez, A., Kelly, G., Li, X., Onogi, K., Saarinen, S., Sokka, N., Allan, R., Andersson, E., Arpe, K., Balmaseda, M., Beljaars, A., van de Berg, L., Bidlot, J., Bormann, N., Caires, S., Chevallier, F., Dethof, A., 
Dragosavac, M., Fisher, M., Fuentes, M., Hagemann, S., Hólm, E., Isaksen, B. H. L., Janssen, P., Jenne, R., McNally, A., Mahfouf, J.-F., Morcrette, J.-J., Rayner, N., Saunders, R., Simon, P., Sterl, A., Trenberth, K., Untch, A., Vasiljevic, D., Viterbo, P., and Woollen, J.: The ERA-40 re-analysis, Q. J. Roy. Meteor. Soc., 131, 2961-3012, 2005. van Bebber, W.: Die Zugstrassen der barometrischen Minima, Meteorol. Z., 8, 361-366, 1891.

Wernli, H. and Schweiz, C.: Surface Cyclones in the ERA-40 Dataset (1958-2001). Part I: Novel Identification Method and Global Climatology, J. Atmos. Sci., 63, 2486-2507, 2006. 